\title{
REDES DE MOVIMENTOS SOCIAIS NA AMÉRICA LATINA - caminhos para uma política emancipatória? ${ }^{1}$
}

\author{
Ilse Scherer-Warren ${ }^{*}$
}

\begin{abstract}
Este texto pretende trazer alguns indicativos para se pensar em que medida as redes de movimentos sociais na América Latina apresentam pistas para políticas emancipatórias. Para se analisar a capacidade ou potencial de redes de movimentos sociais desse continente na construção de referenciais emancipatórios, partiu-se do pressuposto de que demandas materiais devem ser traduzidas em representações simbólicas, a fim de aproximar os atores das redes, permitir a construção de identidades coletivas e criar elos simbólicos de referência no interior das redes, que possibilitem a convergência de suas pautas políticas. Verificou-se, ainda, como a intersubjetividade na rede se constrói a partir de referências normativas compartilhadas e quais os principais níveis constitutivos para o empoderamento de uma rede de movimento. Trata-se, pois, de verificar como atores coletivos específicos, localizados e com demandas particulares, tornam-se movimentos sociais mais abrangentes do ponto de vista de suas demandas e de seus territórios de atuação, com pautas políticas mais universais. Isto é, como está sendo construída a passagem de ações coletivas restritas a movimentos sociais propriamente ditos.

PALAVRAS-CHAVE: redes de movimentos sociais, ações coletivas, América Latina, emancipação, demandas.
\end{abstract}

\section{INTRODUÇÃO - alguns elementos sobre a trajetória dos movimentos sociais na Améri- ca Latina}

É importante relembrar que, na América Latina, a luta emancipatória tem suas raízes em ações de resistência e reivindicativas que se desenvolveram no coração de sistemas sociais altamente excludentes, com profundas desigualdades sociais e com práticas discriminatórias em relação a uma parcela considerável de seus habitantes, além de Estados historicamente oligárquicos e autoritários. Dessa forma, as principais mobilizações populares no período colonial, antes do que antissistêmicas declaradas, foram de rejeição, de negação e de afastamento dos sistemas excludentes (como os movi-

* Doutora em Sociologia. Professora Titular do Departamento de Sociologia e Ciência Política da Universidade Federal de Santa Catarina. Pesquisadora IA do CNPq. Centro de Filosofia e Ciências Humanas, Departamento de Ciências Sociais. Campus Universitário Trindade. Trindade. Cep: 88040-900. Florianopolis - Santa Catarina Brasil. ilse@manezinho.com.br

${ }^{1}$ Temática apresentada como Conferência de abertura à Sessão 4 - O "global" em questão: redes e movimentos sociais transnacionais, no Seminário Nacional "Movimentos Sociais e os novos sentidos da política", 5 a 7 de junho de 2008, PPGCS/UFBA, Salvador. mentos messiânicos, movimentos separatistas, formação de quilombos e resistência indígena), ${ }^{2}$ ou ainda, na mesma lógica separatista, podemos relembrar o anarco-sindicalismo, que vigorou na primeira república brasileira.

É de forma muito acanhada que surgem as primeiras ações coletivas de caráter reivindicativo, especialmente a partir do início no século XX, tais como as de operários, camponeses, indígenas, comunitários cristãos etc. Sem condições de expressarem sua autonomia de sujeito numa esfera pública mais ampla, são politicamente acolhidas por Estados oligárquicos, tutelares ou populistas, caracterizando uma cultura política que pode ser chamada de "estadania", em contraste com a cidadania (Carvalho, 2004, p. 221). Dessa forma, os direitos sociais concedidos pelo Estado, ainda que parciais e focados, frequentemente antecedem a conquista dos direitos civis e políticos, conforme analisa o mesmo autor em relação à realidade brasileira. Será apenas em meados do século XX que

2 Para uma síntese desse momento no Brasil, vide Carvalho, 2004, e, para a América Latina em geral, vide Touraine, 1987. 
as contestações populares assumem um caráter mais politizado, com relativa crítica e autonomia em relação ao Estado, exercendo pressão política para transformações na estrutura social, como as Ligas Camponesas e os movimentos comunitários ligados à teologia da libertação, em vários países latino-americanos e, já nas décadas de 1970-1980, o novo sindicalismo e vários "novos movimentos sociais” na América Latina. ${ }^{3}$

Com as ditaduras militares da segunda metade do século XX, surgem dois principais tipos de manifestações de resistência: por um lado, as organizações clandestinas (guerrilhas e partidos de viés comunista ou socialista); por outro, manifestações cívicas públicas contra o poder autoritário e as restrições aos direitos civis e políticos, geralmente reprimidas pelas forças armadas. Com o processo de democratização, desenvolve-se um movimento cidadão que vai reivindicar a regulamentação ou a criação de novos direitos: civis, políticos, sociais, culturais, étnicos, de gênero e ambientais. $^{4}$

Já no final do século XX e início do novo milênio, as organizações da sociedade civil e os movimentos sociais passam a valorizar cada vez mais formas de participação institucional (audiências públicas, assembléias e conferências políticas, fóruns, conselhos setoriais de políticas públicas, orçamento participativo, Agenda 21, etc.). Tais organizações percebem, nesses espaços, a oportunidade do exercício do "controle social pela cidadania”, considerado como um meio político adequado e legítimo para a expansão da democracia. ${ }^{5} \mathrm{Si}-$ multaneamente, alguns desses movimentos defendem e realizam uma resistência política mais ativa (ocupações de terra, bloqueio de estradas e ocupação de órgãos públicos e de empresas, especialmente transnacionais consideradas nocivas ao meio ambiente ou à participação social dos excluídos na produção social da riqueza, e outras formas de

${ }^{3}$ Sobre o assunto, vide Scherer-Warren; Krischke, 1986; Calderón; Santos, 1987.

${ }^{4}$ Vide depoimentos de vários atores desses tipos de movimentos em Rossiaud e Scherer-Warren, 2000.

${ }^{5}$ Vide maiores desdobramentos sobre a trajetória política dos movimentos sociais no momento pós-ditadura em Scherer-Warren, 2008. intervenção com impacto político). Essa última tendência percebe, nessas formas de resistência, as possibilidades de atuação para "um novo projeto de nação". ${ }^{6}$

O que interessa aqui perceber é que, tanto nos espaços da participação institucional como nos espaços das “assembléias populares" e das redes autônomas dos movimentos sociais, as diferentes organizações e tendências dos movimentos sociais citadas acima se encontram e negociam ações políticas. Isso ocorre porque o movimento social atua cada vez mais sob a forma de rede, que ora se contrai em suas especificidades, ora se amplia na busca de empoderamento político. Portanto, pretende-se examinar, a seguir, como e através de que elementos materiais e simbólicos, referenciais normativos, circuitos identitários e formas de inserção nas redes se constroem nexos politicamente significativos e emancipatórios.

\section{DEMANDAS MATERIAIS E SIMBÓLICAS DOS MOVIMENTOS SOCIAIS}

As demandas materiais têm como referência objetiva as exclusões e carências cotidianas dos sujeitos-base das lutas e são, portanto, histórica e espacialmente referenciadas. Nessa direção, podemos nomear alguns dos movimentos sociais populares mais expressivos na América Latina atual (sem-terra ou campesinos, sem-teto ou de moradores, indígenas, quilombolas, negros, mulheres, piqueteiros, desempregados, dentre outros). Essas demandas se tornam signos e representações simbólicas através da tradução de seus significados em políticas de cidadania. ${ }^{7}$

Portanto, quandonecessidades materiais transformam-se em representações simbólicas de carências de determinados grupos e, consequentemente, eles constroem pautas políticas reivindicativas ou para

${ }^{6}$ Maiores detalhes em Scherer-Warren, 2008.

7 Sobre o trabalho de tradução, vide Santos (2008, p.3031): "A tradução é o procedimento que permite criar inteligibilidade recíproca entre as experiências do mundo, tanto as disponíveis como as possíveis, reveladas pela sociologia das ausências e a sociologia das emergências". 
a transformação social dessa situação, temos o nascimento de uma ação coletiva ou de movimento social específico, ${ }^{8}$ como é frequentemente designado.

Por outro lado, para se entender o potencial de formação de redes de movimentos, ${ }^{9}$ é necessário buscar os nexos que os atores políticos organizados constroem entre as demandas materiais ou as privações no cotidiano e o sentido subjetivo dessas privações, traduzindo esses nexos em formas expressivas, comunicativas e em pautas políticas comuns a várias organizações, criando identidades coletivas que possibilitam a articulação dos movimentos específicos numa rede de movimentos sociais

Os fóruns da sociedade civil organizada e as redes interorganizacionais, ou coletivos em rede, ${ }^{10}$ têm sido espaços privilegiados para a construção desses nexos políticos, conforme constatado e analisado em nossa pesquisa em desenvolvimento. ${ }^{11}$ Com base em relatos de representantes destses fóruns e coletivos em rede, verificamos que:

No combate à exclusão, apresenta-se a necessidade de articular-se a dimensão das condições materiais de existência (desigualdade, pobreza, desemprego, segregação espacial, etc.), com a dimensão das condições simbólica de sua reprodução (estigma, discriminação, desvalorização pessoal e coletiva, etc.) e com as condições políticas de-

${ }^{8}$ Sobre os conceitos de ações coletivas e movimentos sociais vide Scherer-Warren, 1999; 2007b, 2007c.

${ }^{9}$ Las redes de movimientos sociales van constituyéndose en un proceso dialógico: a) de identificaciones sociales, éticas, culturales y/o político-ideológicas, es decir, ellas forman la identidad del movimiento; b) de intercambios, negociaciones, definiciones de campos de conflicto y de resistencia a los adversarios y a los mecanismos de discriminación, dominación o exclusión sistémica, o sea, definen a sus adversarios; c) con vistas a la transposición de los límites de esta situación sistémica en dirección de la realización de propuestas o proyectos alternativos, es decir, establecen sus objetivos, o construyen un proyecto para el movimiento (Scherer-Warren, 2006c.)

${ }^{10}$ Coletivos em rede referem-se a conexões entre organizações empiricamente localizáveis (p.ex., entre ONGs ambientalistas). Estes coletivos podem vir a ser segmentos (nós) de uma rede mais ampla de movimentos sociais, que por sua vez é uma rede de redes. O Fórum Brasileiro do ONGs e Movimentos Sociais para o Meio Ambiente e o Desenvolvimento é uma sub-rede do movimento ambientalista brasileiro. Entretanto, o movimento social deve ser definido como algo que vai além de uma mera conexão de coletivos. (vide Scherer-Warren, 2007c, p. 328).

${ }^{11}$ Projeto AMFES - As múltiplas faces da exclusão social, NPMS/CNPq, em andamento, coordenado por Ilse Scherer-Warren. Outros detalhes em Scherer-Warren, 2006a e 2007a. correntes (subcidadania, desempoderamento, etc.) (Scherer-Warren, 2007, p. 37 Projeto AMFES).

Em última análise, trata-se de traduzir as demandas específicas e particulares em ideários politicamente mais amplos, mas suficientemente inclusivos em relação às desigualdades e discriminações históricas diferenciadas. Não se trata de recorrer a um universalismo abstrato, sem referência concreta e substantiva ao cotidiano dos sujeitos submetidos à exclusão ou à discriminação; nem a um relativismo da diferença que não considere os possíveis processos de opressão ao “diferente”. Segundo Boaventura Santos (2004), há que se superarem os falsos debates sobre universalismo e relativismo cultural,

... cujos conceitos polares são igualmente prejudiciais para uma concepção emancipatória de direitos humanos. Todas as culturas são relativas, mas o relativismo cultural, enquanto atitude filosófica, é incorreto. Todas as culturas aspiram a preocupações e valores universais, mas o universalismo cultural, enquanto atitude filosófica, é incorreto. Contra o universalismo, há que propor diálogos interculturais sobre preocupações isomórficas [isto é, que possam convergir numa unidade valorativa]. Contra o relativismo, há que desenvolver critérios políticos para distinguir política progressista de política conservadora, capacitação de desarme, emancipação de regulaçã̃o.

O autor propõe, como solução para esse impasse, a prática do diálogo intercultural e da hermenêutica diatópica, através da qual as diferentes culturas passam a refletir sobre suas próprias construções (topoi) e a reconhecer as concepções mais abrangentes das outras culturas (topoi alheio). ${ }^{12}$ Esse diálogo intercultural pode facilitar a formação de "redes de referências normativas capacitantes", conforme veremos mais adiante.

Nesse processo dialógico, há que se considerar a forma da relação intergrupal, se construída de forma democrática ou em torno de um centralismo autoritário; a existência ou não de reconhecimento recíproco sobre a vivência da exclusão ou da discriminação dos sujeitos; e, além disso, a tradução dessa vivência em novos valores

${ }^{12}$ Vide também, a este respeito, Santos (2003b, p.429-461). 
coletivos dos grupos, na definição dos conflitos geradores da exclusão e dos principais adversários políticos. E, enfim, como esse processo reverte positivamente na construção de pautas para as políticas emancipatórias que conectam as várias particularidades dos indivíduos em redes normativas mais abrangentes, contribuindo para a transformação dos indivíduos participantes em sujeitos de direito. Ou, ainda, conforme ressalta Touraine (1994b):

Uma sociedade democrática é uma sociedade que reconhece o outro, não na sua diferença, mas como sujeito, quer dizer, de modo a unir o universal e o particular [...], uma vez que o sujeito é ao mesmo tempo universalista e comunitário e ser sujeito é estabelecer um elo entre esses dois universos, ensaiar viver o corpo e o espírito, emoção e razão (p. 1-2). ${ }^{13}$

Porém é sempre bom relembrar que não há imperativo causal algum entre a vivência do "corpo" (a materialidade) e do "espírito" (especialmente a subjetividade coletiva). A possibilidade da construção de sujeitos e da transformação desses sujeitos em atores politicamente ativos não transcorre como uma necessidade imediata da vivência de carências. A carência por si só não produz movimentos sociais. O movimento resulta do sentido coletivo atribuído a essa carência e da possibilidade de identificação subjetiva em torno dela. Resulta também da subsequente transformação dos sujeitos em atores políticos, da respectiva transformação das carências em demandas, desstas demandas em pautas políticas e das pautas políticas em ações de protestos. Além disso, para se observar o surgimento de um movimento social propriamente dito, esse deve ter a capacidade de autoidentificação coletiva em torno de conflitos, de adversários centrais a serem enfrentados e da construção de projetos e utopias de mudança. ${ }^{14}$ Mas

13 "Rencontre avec Alain Touraine". Entretien avec JeanFrançois Dortier et Patrick Maret. Mensuel, n. 42, ago., 2005. Disponível em: www.ac-corse.fr/disciplines/ scienceseco/Atour1.html. Acesso em: 25 maio 2006. Apud Gadea e Scherer-Warren, 2005.

${ }^{14}$ A passagem de um movimento meramente reivindicativo para um movimento social propriamente dito requer a realização de três passos: 1 . A identidade coletiva ou identificação em torno de uma causa comum; 2. A definição de uma situação de conflito e de seus adversários; 3. Um projeto ou utopia de mudança. Vide, a esse res- sem dúvida, nessa dialética, as referências normativas do cotidiano e sua transformação em ideários para o movimento são politicamente relevantes, conforme veremos a seguir.

\section{REFERÊNCIAS NORMATIVASE INTERSUBJETIVIDADE NAS REDES}

Ainda de acordo com Boaventura Santos (2008b), a concepção emancipatória dos direitos humanos não deveria recorrer a falsos universalismos, conforme já dito, mas deveria se organizar como uma constelação de sentidos locais mutuamente inteligíveis que, assim, poderia vir a se constituir em redes de referências normativas capacitantes. O autor acrescenta que "o potencial antissistêmico ou contra-hegemônico de qualquer movimento social reside na sua capacidade de articulação com outros movimentos, com as suas formas de organização e os seus objetivos. Portanto, para que essa articulação seja possível, é necessário que os movimentos sejam reciprocamente inteligíveis". Tal inteligibilidade pode ser conseguida, segundo ao autor (2008a), através do trabalho de tradução que:

... visa a esclarecer o que une e o que separa os diferentes movimentos e as diferentes práticas, de modo a determinar as possibilidades e os limites da articulação ou agregação entre eles. Dado que não há uma prática social ou um sujeito coletivo privilegiado em abstrato para conferir sentido e direção à história, o trabalho de tradução é decisivo para definir, em concreto, em cada momento e contexto histórico, quais as constelações de práticas com maior potencial contrahegemônico.

É dentro dessa lógica que a Via Campesina tornou-se um elo relevante na rede de movimentos sociais rurais em vários continentes na luta antissistêmica frente ao modelo do agronegócio. A "Campanha das sementes" tornou-se um signo emblemático sobre produção e qualidade de vida, mobilizando não apenas os movimentos camponeses mais consolidados, como o MST, mas tam-

peito, Touraine, 1987 e também Scherer-Warren, 1999, 2000 e $2007 \mathrm{~b}$ 
bém os mais recentes, como o das mulheres e dos jovens, na medida em que suas questões específicas puderam ser traduzidas para novos significados, de acordo com uma visão de mundo mais igualitário, mais saudável e mais justo. Niemeyer (2006), em tese sobre o assunto, diz que, na "Campanha das sementes",

... a problemática camponesa seria conceituada de forma abrangente, associando questões que, no conjunto, corresponderiam aos direitos dos camponeses. Apesar de o foco estar nas sementes e na luta contra a propriedade intelectual dos recursos genéticos, estas questões são associadas a outras questões-chave como soberania alimentar, cultura, gênero, desenvolvimento, propriedade intelectual, meio-ambiente, trabalho, direitos humanos, saúde e consumo (p. 119).

A rede da Via Campesina ${ }^{15}$ que se expandiu no contexto das realizações do Fórum Social Mundial, criou seu espaço próprio de articulação política global e na América Latina. Em 2004, foi realizada a IV Conferência Internacional da rede, no Brasil (Itaicí/SP), sob o lema: "Globalizemos a luta, globalizemos a esperança". Os temas da soberania alimentar, das sementes transgênicas e da reforma agrária foram centrais. Representantes de organizações camponesas de 80 países compareceram, dentre as quais 18 países de América Latina e Caribe. Nesse encontro, foram realizadas a "II Assembléia de Mulheres da Via Campesina” e a "I Assembléia de Jovens Camponeses da Via Campesina”, ${ }^{16}$ articulações que praticaram um ativismo de ação direta nos anos subsequentes, como nas ocupações dos canteiros da Aracruz Celulose, no Rio Grande do Sul. As manifestações também têm sido em solidariedade aos indígenas e quilombolas, especialmente do Espírito Santo, que perderam suas terras para a referida empresa, bem como contra o mercado de

15 A Via Campesina é uma articulação de movimentos camponeses, e está presente em quatro continentes. No Brasil, o MST compõe a Via com o MAB (Movimento dos Atingidos por Barragens), MPA (Movimento dos Pequenos Agricultores), Movimento das Mulheres Camponesas (MMC), PJR (Pastoral da Juventude Rural), CPT (Comissão Pastoral da Terra), Abra (Associação Brasileira de Reforma Agrária), Feab (Federação dos Estudantes de Agronomia), PJR (Pastoral da Juventude Rural), indígenas e quilombolas.

${ }^{16}$ Vide maiores desdobramentos em Niemeyer, 2006. transgênicos praticado pela Monsanto, Syngenta e Stora Enso. ${ }^{17}$

As questões da solidariedade entre sujeitos coletivos, do reconhecimento a partir ou apesar de suas diferenças e a abertura ao pluralismo democrático são fundamentais para que ocorra a transformação das demandas particulares em pautas políticas que dizem respeito a um conjunto de exclusões sociais que operam numa mesma ordem ou lógica sistêmica. É a partir de uma nova lógica associativa que a diversidade dos movimentos sociais latinoamericanos vem se articulando em redes políticas, como foi constatado no estudo de Korol (2007):

Conviven en el pueblo organizaciones tradicionales, como los sindicatos, centrales campesinas, estudiantiles, barriales; movimientos nacidos como respuesta a la exclusión, o a partir de búsquedas de reconocimiento; movimientos que plantean demandas económicas o culturales. Conviven movimientos estructurados de manera fuertemente jerárquica, basados en la separación de dirección y bases; y otros con dinámicas asamblearias, o de horizontalidad, que suelen tener grandes diûcultades para crear un auténtico protagonismo de las mayorías, y que tienden a desestructurarse con facilidad (p. 7).

Se, por um lado, esse encontro da diversidade dos movimentos representa também a possibilidade de fragilidade das lutas, devido à sua fragmentação e efemeridade, por outro lado, representa um avanço no plano do reconhecimento intersujeitos e interorganizacional, criando um potencial de democratização no âmbito das relações sociais e políticas. Portanto, opera-se uma dialética em que não apenas o sujeito torna-se ator, conforme afirma Touraine, mas em que o ator, em sua prática movimentalista, vai se transformando em sujeito político, ${ }^{18} \mathrm{o}$ que, para as camadas subalternas na América Latina, é um acontecimento político relevante, em termos sociais e culturais. É a passagem do indivíduo (do individualismo) ao sujeito (da política do reconhecimento). Isso ocorre porque, segundo Machado (2007, p. 277), vivemos numa era em que 17 Maiores detalhes em: www.mst.org.br/mst/
pagina.php?cd $=5066$
18 Vide, a esse respeito, os resultados da pesquisa de
Silveira, 2007, sobre os sujeitos do MST. 
os interesses dos indivíduos que os ligam em redes são cada vez mais cruzados, diversos e, frequentemente, tênues. Luta-se cada vez mais em torno de códigos culturais, valores e interesses diversos. Essa luta se dá, cada vez menos, a partir dos indivíduos e mais sobre a construção de sujeitos sociais.

Porém o encontro e, frequentemente, o desencontro dos códigos culturais, dos interesses específicos e das concepções político-ideológicas de diferentes organizações na rede são produtores de tensões e conflitos internos nem sempre superáveis, pelo menos, de imediato. Esse é um desafio necessário do jogo da negociação democrática agonística (Mouffe, 2003, p.19), isto é, de uma democracia pluralista, "que valoriza a diversidade e o dissenso e não tenta estabelecer uma esfera pública a partir de sua eliminação”. Uma das tensões mais frequentes ocorre entre visões distintas no interior das redes sobre os caminhos políticos para os processos de transformação social. De um lado, pode-se observar uma concepção que privilegia a determinação da classe para a transformação nas demais esferas sociais e culturais; de outro, uma concepção que privilegia os nexos e tensões entre igualdade e diferença. Uma dessas tensões pode ser observada na posição das denominadas "esquerdas" e de alguns movimentos sociais em relação às políticas de cotas nas universidades brasileiras. Os partidários da primeira concepção defendem uma política de cotas exclusivamente social (para estudantes oriundos de escolas públicas), a partir do pressuposto de que a desigualdade social é determinante das demais esferas da vida social. Os defensores da segunda concepção defendem uma política de cotas sociais e étnicas (incluindo cotas para negros e indígenas), partindo do pressuposto de que, para além dos nexos estruturais entre desigualdade e diferença, há uma relativa autonomia entre os processos sociais e culturais, com discriminações históricas consolidadas que transcendem e, frequentemente, ultrapassam, em intensidade, as condições das desigualdades socioeconômicas, como é o caso do racismo. ${ }^{19}$

${ }^{19}$ Estamos aqui apenas nos referindo a grupos de intelec tuais e de movimentos sociais defensores das cotas, porém há também, no Brasil, grupos organizados contra-
Em última instância, muitas vezes também se encontram subjacentes à primeira concepção os princípios universalistas da "igualdade formal" e da "liberdade individual", pretendendo-se, segundo essa proposta, eliminar as desigualdades sociais unicamente através de políticas universais. Entretanto, essas já não condizem com a complexidade das relações e respectivas contradições da sociedade contemporânea, conforme crítica de Hall (2003):

Assim, não podemos simplesmente reafirmar a liberdade individual e a igualdade formal [...], pois podemos perceber o quanto ambas são inadequadas às complexidades de vínculo, pertencimento e identidade introduzidas pela sociedade multicultural, e como as profundas injustiças, exclusões sociais e desigualdades continuam a ser perpetradas em seu nome.(p. 88)

Numa outra direção, em nossa pesquisa sobre fóruns da sociedade civil brasileira, observamos que o embate entre "diferença e igualdade" tem feito avançar o pluralismo democrático agonístico no interior de alguns coletivos em rede, como no exemplo abaixo, da Articulação das MuIheres Brasileiras (AMB): ${ }^{20}$

Existe um conflito salutar, que tem feito a AMB crescer e se diferenciar, que é o conflito que traz as organizações de mulheres indígenas e as organizações de mulheres negras para dentro da $\mathrm{AMB}$, e agora também as organizacões de lésbicas. E toda a coisa "da diferença e da igualdade" que essas organizações trazem, e que sempre gera conflito. Nós temos conseguido lidar de uma maneira muito positiva com isso, com esses conflitos, nós temos crescido com isso. A AMB que era simplesmente Articulação de Mulheres Brasileiras, agora carrega um subtítulo que diz AMB - uma articulação feminista e anti-racista. Isso se definiu afirmando o feminino e também afirmando o anti-racismo como uma questão central. Isso tudo é fruto das mulheres negras dentro da AMB, de dez anos para cá. Porque lá no processo de Bejing, lá atrás, isso não era tema.

Segundo Santos (2007, p. 62-64), para se construir a emancipação, há que se contemplar a relação entre o respeito da igualdade e o princípio

cotas, especialmente para negros. Sobre as retóricas contra e a favor das cotas nas universidades, vide Goss, 2008.

${ }^{20}$ Entrevista concedida por representante da AMB ao Projeto AMFES, op. cit. Essa concepção normativa também se encontra na Marcha Mundial das Mulheres, que articula o feminismo latino-americano. 
do reconhecimento da diferença. Nessa relação, há formas híbridas que se identificam com elementos da desigualdade (referente a um sistema de domínio hierarquizado, "onde o que está embaixo está dentro") e de exclusão (referente a um sistema de domínio hierarquizado, "onde o que está embaixo está fora”, sendo que as duas formas mais importantes para o autor são o racismo e o sexismo. Portanto, quando as redes de movimentos sociais encontram-se abertas para o diálogo intercultural, para a superação dos conflitos decorrentes de referenciais normativos de sujeitos coletivos diferenciados, enfrentado formas híbridas de desigualdade ou exclusão, conforme exemplos empíricos acima citados, onde os conflitos raciais, de gênero e homofóbicos são enfrentados e coletivamente retrabalhados, o movimento poderá estar caminhando para um processo de emancipação coletiva mais abrangente e profunda na América Latina. Numa última dimensão, discutiremos em que medida os níveis constitutivos de uma rede também teem implicações em sua democratização interna e em seu empoderamento na esfera pública.

\section{NÍVEIS CONSTITUTIVOS DE UMA REDE DE MOVIMENTOS SOCIAIS}

Cohen estabelece os seguintes níveis na análise do formato de rede, que incidem em seu empoderamento: organizacional, narrativo, doutrinal, tecnológico e social.

A rede será forte se incluir uma história que persuade e integra seus membros; se abranger estratégias e métodos colaborativos baseados em uma doutrina bem definida; se utilizar sistemas avançados de comunicação e apoiar-se em vínculos sociais e pessoais fortes (2003, p. 436).

Sobre o nível organizativo muito tem sido dito sobre as diferenças, na teoria, entre uma organização em rede e uma organização hierárquica. ${ }^{21}$ Interessa aqui apenas relembrar a especificidade ${ }^{21}$ Tratei dessas perspectivas em vários trabalhos anteriores; redes nos movimentos sociais em Scherer-Warren, 2007c. na prática dos movimentos sociais em rede, os quais, frequentemente, têm integrado uma ampla multiplicidade de atores políticos, alguns oriundos de tradições organizativas mais hierárquicas, e outros que emergem no contexto de um novo ideário de organização em redes horizontalizadas. Essa condição, por um lado, gera tensões e ambiguidades no interior das redes, mas, por outro, cria um espaço propício para a alteridade intersujeitos e para práticas democratizantes, conforme já mencionado.

O pluralismo das tradições organizativas, oriundas de métodos de trabalho diferenciado, gera necessidade de negociações e de reconhecimento mútuo de suas diferenças no interior da rede, como observamos em nossa pesquisa com o Fórum $\mathrm{Na}$ cional de Reforma Agrária e Justiça no Campo (FNRA) ${ }^{22}$ em relação a entidades de tipo sindical (modelo piramidal) e do "movimento de massa" (modelo basista e mais horizontalizado):

Aí temos um divisor de águas. Existe uma divisão clara de pensamento entre os movimentos de massa em geral (como o MST) e o movimento sindical (como a CONTAG) ${ }^{23}$... Qual é o método de ação? A CONTAG tem o método de negociar, fazer o protocolo, o presidente do sindicato vai lá, protocola e vai para casa. E pede para os filiados ficarem esperando, isso na maioria dos casos. Isso é um problema de concepção de método de luta, porque a essência da ação deles é a negociação e não a ação. E no movimento de massa já é diferente, o movimento usa os dois métodos - a negociação e a ação. Qual é a diferença da ação entre o movimento de massa e o movimento sindical? A CONTAG antes de começar a luta vai lá e entrega a pauta para o governo, e só vai com a ação para receber a resposta do governo. Isso não é luta, isso não politiza ninguém. No movimento social é diferente, a luta faz a luta, a negociação e o resultado da negociação é resultado da luta.

Segue-se como o FNRA vem atuando com a diversidade nos métodos de ação, ou que método o fórum adota, como rede, para equacionar essa tensão?

\footnotetext{
${ }^{22}$ Entrevista com representante concedida ao Projeto AMFES, op. cit.

${ }^{23}$ Trata-se de dois atores estratégicos no interior do fórum; todavia devemos dizer que o FNRA é composto de várias dezenas de organizações que trabalham com a questão rural.
} 
Respeitando as diferenças, quando fazemos uma Campanha como essa, não vamos tirar uma semana para todo mundo fazer a mesma coisa, isso não funciona. Faz aquilo que ele sabe fazer, do jeito dele, com o mesmo objetivo. Se o movimento sindical quer fazer 500 audiências, ótimo, então 500 audiências para cobrar do governo isso aqui (Carta da Terra). ${ }^{24}$ A Carta da Terra é o nosso modelo, mas o método da ação é deles, vamos respeitar eles. O MST vai fazer uma marcha, vai chegar aqui em Brasília com 30, 50 mil pessoas, ótimo, é o jeito dele, vamos apoiar. Vamos apoiar a negociação e vamos apoiar eles. Porque senão o Fórum vira uma camisa de força, enquadrando todo mundo. Não somos uma federação. Temos que fortalecer as ações dos movimentos pela unidade, e não fortalecer as diferenças para a briga (Projeto AMFES, 2007).

Portanto, é nesse embate, entre respeito à diversidade (dentro de determinados limites ideológicos, naturalmente) e a busca da unidade possível na ação (não necessariamente homogênea, mas complementar), que as redes de movimentos sociais vêm construindo suas trajetórias. Dessa forma, o ideário de horizontalidade organizacional é permeado pela existência de elos internos que atuam a partir de representações políticas formalmente mais hierarquizadas. Além disso, é necessário lembrar que, mesmo nas organizações de base, há delegações de poder, necessárias à eficácia e à viabilização da participação em práticas políticas, especialmente as institucionais.

Quanto ao nível das narrativas e o doutrinário, percebe-se que, nas redes de movimentos sociais latino-americanas, esses dois níveis tendem a se articular nas práticas discursivas atuais, aproximando a memória da exclusão e da discriminação com o seu legado no presente, fruto desse processo histórico. É dessa forma que redes de mulheres, de indígenas, de negros e de camponeses relembram a tradição colonial, patriarcal e patrimonial, o poder das oligarquias locais, a expropriação no campo econômico e a subordinação nos campos políticos, sociais e culturais. O depoimento abaixo é ilustrativo dessa condição: ${ }^{25}$

$24 \mathrm{Na}$ mesma entrevista, foi acrescentado que o elo de união, na rede, encontra-se na Carta da Terra, em relação a qual até a CONTAG “assinou, ajudou a construir. A Carta da Terra hoje é o nosso documento principal. Até que mude esse cenário, em que estamos vivendo, será o nosso documento guia”.

${ }^{25}$ Vide Scherer-Warren (2006b, p.132).
Nós, mulheres índias e negras, reunidas na $1^{\mathrm{a}} \mathrm{Con}-$ ferência Nacional de Políticas para as Mulheres, realizada de 15 a 17 de julho de 2004 em Brasília - DF, selamos uma aliança de parentesco:

- considerando a semelhança da opressão colonial sofrida pelos povos indígenas e afrodescendentes, em especial as mulheres;

- considerando que esses dois povos foram igualmente submetidos a processos de genocídio e/ou extermínio;

- considerando o estupro colonial, perpetrado contra índias e negras;

- considerando a espoliação e expropriação das terras, das culturas, dos saberes desses dois povos; - considerando a perpetuação da exclusão histórica desses povos desde o término do período colonial até os nossos dias, que vitima especialmente as mulheres, distorcendo e desvalorizando suas imagens;

- considerando a necessidade da reparação histórica que o Estado brasileiro tem para com esses povos em geral e as mulheres em particular.

E, do ponto de vista propositivo e estratégico para as lutas sociais de forma articulada, acrescentam:

\section{Decidimos:}

- Firmar o nosso parentesco através de uma aliança política na busca conjunta de superação das desigualdades econômicas, políticas, sociais, culturais e de poder;

- Firmar uma aliança estratégica para a conquista da igualdade de oportunidades para mulheres índias e negras na sociedade brasileira;

- Firmar uma aliança estratégica que dê visibilidade a índias e negras como sujeitos de direito.

Doravante índias e negras consideram-se parentes.

A estratégia política de uma aliança de parentesco é construída a partir de um trabalho de tradução de vivências históricas semelhantes, porém não necessariamente idênticas, cuja subjetividade, construída a partir do sofrimento no presente, permite a construção de uma identidade comum em torno de uma utopia emancipatória. Em relação aos povos mais excluídos e discriminados social e culturalmente na América Latina, ainda há um lugar para a associação das narrativas históricas de reparação, com os ideários presentes nas lutas para a construção de sujeitos de direito, conforme reivindicado no documento acima. Portanto, há um encontro e um desencontro em relação ao que foi concluído por Touraine (2007), em seu estudo sobre a sociedade das mulheres na França, quando diz que: 
... a análise dos atores tornou-se mais importante do que a análise das situações, visto que não acreditamos mais naquilo que Jean-François Lyotard chamou de "grandes narrativas", nas filosofias da história, e em particular nas duplas oposições binárias. A idéia de uma infraestrutura determinando as formas da vida política e as ideologias já nos é estrangeira (p. 163).

De fato, as filosofias da história, como teleologias, e as decorrentes oposições binárias, como determinismos, de uma forma geral tendem a ser rejeitadas aqui e acolá, como frutos do diálogo de redes mais amplas dos movimentos transnacionais nas diversas áreas. Porém as narrativas históricas estão sendo reescritas na América Latina pelos movimentos indígenas, dos negros, dos sem-terra, das mulheres e outros, de forma crítica às narrativas hegemônicas da "democracia racial”, da "homogeneidade cultural”, "do homem cordial" e outras semelhantes.

A releitura da história e a sua tradução em novas referências simbólicas e ideários que encontram ecos no cotidiano dos grupos subalternos criam condições propícias para que eles se relocalizem em relação à herança social de sua condição humana, recuperem e re-interpretem signos culturais (por exemplo, o de raça e o de etnia), construam identidades coletivas e se reconheçam mutuamente como sujeitos de direitos.

No nível da informação e da comunicação, as novas tecnologias têm um papel relevante para a formação de uma sociedade civil cada vez mais ampla e mundializada. Tanto o movimento altermundialização quanto as redes de movimentos específicos têm se beneficiado desses recursos, não só para a comunicação inter-rede, mas também na construção de uma rede de simpatizantes, de solidariedade e na formação de uma “opinião pública mundial” e (ou) latino-americana, a partir de uma sociedade civil crítica. O primeiro exemplo que provocou um forte impacto nessa opinião pública mundializada foi o movimento neozapatista de Chiapas, no México, o que levou Castells (1996) a defini-lo como a "primeira guerrilha informacional". ${ }^{26} \mathrm{O}$ que interessa enten-

${ }^{26}$ Para uma análise detalhada desste movimento, vide Gadea, 2004. der aqui é como esse recurso tecnológico contribuiu para o encontro de um movimento indígena localizado com redes transnacionais ou, conforme relato de Gadea, ao chegar à Selva Lacandona, Chiapas, como se encontra a ocultação histórica e o não-reconhecimento dos povos indígenas: “... se percebe como o colonial não é uma época histórica, algo do passado, [...] mas que a presença indígena, hoje, sustenta que a realidade colonial continua vigente em Chiapas (2004, p. 66)”. Essa situação de exclusão foi reinterpretada e ressignificada através das redes virtuais, para outras formas de exclusão e resistência na modernidade:

A composição social indígena com demandas cidadãs parecem definir o espaço local identitário e o espaço nacional de projeção política, enquanto o transnacional se consolida nas redes de identidade ou comunidades de resistência criadas, aparecendo em seu imaginário discursivo palavras como diferença cultural, diversidade, biodiversidade, pluralismo, defesa da identidade humana e solidariedade. A partir desta justaposição de espaços, se evidencia a flexibilidade constitutiva da identidade, estratégia e demandas do movimento neozapatista, sua capacidade de articulação como ator coletivo num cenário "sem fronteiras precisas", onde os "inconformados e rebeldes de todo o mundo", "os excluídos da modernidade, tecem as resistências", como afirma o subcomandante Marcos (Gadea, 2004, p. 247-248).

Enfim, as novas tecnologias, especialmente a internet e as rádios comunitárias, ${ }^{27}$ são um elemento facilitador na difusão das narrativas e ideários em construção pelos sujeitos, nós das redes, mas geralmente não são o único ou principal elemento mobilizador na geração de uma rede de movimento social, o que é referendado por representante do MST em pesquisa realizada por Orrico Rocha (2004):

O MST reconhece que a internet é uma ferramenta de luta importante para os movimentos sociais da atualidade, e destaca que ela permite um rompimento com o olhar da mídia tradicional que enxerga no movimento uma negação da ordem legal da sociedade; por outro lado, os semterra não acreditam que a internet seja a "principal” ou "única" forma de ação dos movimentos

${ }^{27}$ Essas rádios comunitárias conseguem atingir as populações mais carentes, excluídas digitais, divulgando mensagens dos movimentos sociais e mobilizando para a participação em reuniões e eventos. 
sociais deste início de século XXI. Para eles, a força de um movimento social continua sendo a sua capacidade de organização e mobilização.

Isso nos remete ao quarto elemento constitutivo de uma rede - os vínculos sociais e pessoais e sua capacidade de gerar mensagens de conexão, mobilização e empoderamento. Na pesquisa sobre os fóruns da sociedade civil, ${ }^{28}$ constatou-se que, em sua totalidade, eles utilizam formas de comunicação virtual para se relacionar com seus membros e para gerar informação. Há um amplo esforço para atingir as bases de referência dos fóruns pois se considera que a relação interindividual e interorganizacional é necessária na construção do coletivo e da identidade dos movimentos. No caso da comunicação virtual, tem sido feito um esforço institucional para disponibilizar meios eletrônicos (acesso à internet e a e-mails nas sedes de ONGs ou de associações filiadas).

Porém os encontros presenciais (reuniões, seminários, assembléias, etc.) continuam sendo muito valorizados, pois neles é onde ocorre o debate mais profundo, a experiência da prática na política, os vínculos mais duradouros no interior da rede. A forma virtual e a presencial de comunicação se complementam, na medida em que a primeira é mais ágil, mais ampla e, às vezes, com menos custos individuais; a segunda é mais intensa, ainda que de mais difícil realização nos fóruns mais amplos, conforme afirmou uma representante do Fórum Nacional da Mulher Negra:

\begin{abstract}
... a gente tem pegado carona em outros eventos. Falta de recursos. Quando vai ter uma reunião tal, a gente liga para fulano: - Você tem que participar desse evento aí, para você vir para a gente se reunir. É isso que tem acontecido, é carona mesmo.
\end{abstract}

A partir dos vínculos sociais e políticos interindividuais e interorganizativos, as redes de movimentos desenvolvem seus processos mobilizatórios em espaços locais ou regionais, mas, de forma articulada buscam impacto midiático, visibilidade numa esfera pública ampliada, desenvolver estratégias políticas e propostas programáticas em torno de suas necessidades e de sua noção de direitos, ${ }^{28}$ Vide Projeto AMFES, op. cit. conectando os espaços locais com espaços nacionais, regionais e internacionais. Bringel e Falero, em análise das relações do MST do Brasil e do FUCVAM (Federação Uruguaia de Cooperativas de Moradia por Ajuda Mútua) com as redes transnacionais de apoio, observaram que essas organizações buscam construir alianças transnacionais com "o objetivo de construir alternativas de sociedade e projetar novos eixos de resistência regional, no caso latino-americano". Acrescentam que, dessa forma, "a resolução de uma necessidade como o acesso à terra ou à moradia pode ser construída socialmente como um direito, com um sentido emancipatório frente ao projeto do capital” (Bringel; Falero, 2008, p. 282).

Além disso, a partir de eventos ou datas comemorativas, várias redes vêm construindo um conjunto de mobilizações simultâneas. Por exemplo, o dia 8 de março é data de mobilização da Marcha Mundial das Mulheres (MMM), em vários continentes, na América Latina e em vários locais, conectando-se com as múltiplas redes femininas, feministas e de movimentos simpatizantes. Dessa forma, a MMM conecta suas questões específicas com questões mais gerais dos movimentos em rede. Em 2008, o eixo foi:

Mulheres em luta por igualdade, autonomia e
soberania popular, que reafirma a luta para mu-
dar a vida das mulheres imbricada à luta para
mudar a sociedade. Para isso, o feminismo deve
incorporar as dimensões de raça/etnia, sexuali-
dade, classe e toda diversidade que há entre as
mulheres, numa perspectiva de solidariedade...
Neste marco, a integração latino-americana des-
de os povos é uma batalha a ser travada para a
construção de nossa emancipação como conti-
nente. (Boletim da Marcha, 2008).

É a partir desse encontro de uma pluralidade de demandas, de lutas por reconhecimentos específicos, de definição de conflitos e de adversários particulares e sistêmicos e à luz de um projeto popular mais amplo de integração latino-americana, que contemple a participação política e autônoma dos sujeitos coletivos, que os movimentos ditos populares, através de suas redes, vêm se fortalecendo no continente, sendo uma referência política relevante para vários governos. 


\section{CONCLUINDO}

As redes de movimentos sociais, na atualidade, caracterizam-se por articular a heterogeneidade de múltiplos atores coletivos em torno de unidades de referências normativas, relativamente abertas e plurais. Compreendem vários níveis organizacionais - dos agrupamentos de base às organizações de mediação, aos fóruns e redes políticas de articulação. ${ }^{29}$ Essas redes ora têm como nexos uma temática comum (terra, moradia, trabalho, ecologia, direitos humanos etc.), ora uma plataforma de luta política mais ampla (a altermundialização, a soberania nacional, um projeto de nação, ou a luta contra o neoliberalismo, contra a hegemonia mundial do capitalismo, as guerras imperialistas, contra o monopólio dos meios de comunicação, dentre outras), indicando uma relativa volatilidade das redes, mas também sugerindo indícios de sua capacidade de abertura ao pluralismo democrático agonístico (vide Mouffe, 2003).

O encontro em torno das demandas materiais mais específicas contribui para a construção de identidades coletivas mais restritas, frequentemente na luta por direitos humanos setorizados. ${ }^{30}$ Já o encontro em torno das plataformas mais gerais contribui para a emergência de movimentos de resistência antissistêmica na América Latina. No último caso, trata-se de redes de redes de movimentos sociais, multi-identitárias e multissetoriais, translocais e transnacionais. É nesse contexto que os movimentos dos sem-terra, indígenas, camponeses, feministas, estudantes, moradores, negros, pastorais sociais, desempregados, piqueteiros, da economia solidária, lutas pela água, atingidos pelas barragens, ecológicos etc., em crescimento em vários países da América Latina, dialogam entre si, traduzindo suas especificidades em sentidos comuns da luta de resistência antissistêmica. Além das trocas virtuais, há lugares privilegiados para esses diálogos ou manifestações intersetoriais,

${ }^{29}$ Para uma explicitação destes níveis, vide Scherer-Warren, $2006 a$.

${ }^{30}$ Vide detalhes dessas lutas na América Latina em Jelin e Hershberg, 2006; Carvalho, 2004, e alguns exemplos em Scherer-Warren, 2006b. como nos Fóruns Sociais Mundiais, na MMM, ${ }^{31}$ nas manifestações da Via Campesina, nos encontros paralelos às Cúpulas Mundiais, ${ }^{32}$ dentre outros. Na III Cúpula dos Povos, realizada em 2008 na América Latina, foi concluído que, enquanto os governantes reunidos em Lima falavam sobre coesão social, mudanças climáticas e redução da pobreza, os movimentos e organizações sociais afirmavam que "a principal causa da desigualdade, da discriminação e da degradação ambiental é a primazia dos mercados sobre os direitos humanos". ${ }^{33}$

Enfim, as redes de movimentos sociais, na América Latina, vêm construindo caminhos para uma política emancipatória, na medida em que se apresentam abertas à diversidade das organizações sociais da região, vêm colaborando para reescrever a história de ocupação e a de dominação em cada país, traduzindo-as em simbologias e significados para as populações mais excluídas, discriminadas e dominadas no presente, criando utopias de transformação que foram unificadas no lema "um outro mundo é possível” e suas variações de interpretação.

(Recebido para publicação em outubro de 2008) (Aceito em dezembro de 2008)

\section{REFERÊNCIAS}

BOLETIM DA MARCHA, n.46, abr., 2008.

BRINGEL, Breno; FALERO, Alfredo. Redes transnacionais de movimentos sociais na América Latina e o desafio de uma nova construção socioterritorial. Caderno CRH: revista do Centro de Recursos Humanos da UFBA, Salvador, v. 21, n. 53, p. 269-288, maio/ago., 2008.

CALDERÓN, Fernando; SANTOS, Mario R. dos (Comp.) Los conflictos por la constitución de un nuevo orden. Buenos Aires: CLACSO, 1987.

${ }^{31}$ Realizadas anualmente na América Latina, em sintonia com o mesmo movimento globalizado.

${ }^{32}$ Como a III Cúpula dos Povos, paralela à $5^{\mathrm{a}}$ Cúpula $d a$ América Latina, Caribe e União Européia, que reuniu chefes de Estado das três regiões, recentemente no Peru. Sobre as diferentes estratégias (contra-cúpulas, manifestações e fóruns) do movimento anti-globalização, vide a obra de divulgação de Echart, López e Orozco, 2005.

${ }^{3}$ Agência Brasil, 16 maio 2008. Disponível em: www.agenciabrasil.gov.br/noticias 
CARVALHO, José Murilo de. Cidadania no Brasil: o longo caminho. Rio de Janeiro: Civilização Brasileira, 2004.

CASTELLS, Manuel. The power of identity. The information age: economy, society and culture. Cambridge, MA; Oxford, UK: Blackwell, 1997. v. 2.

COHEN, Jean. Sociedade civil e globalização: repensando categorias. DADOS: revista de Ciências Sociais, Rio de Janeiro, v. 46, n. 3, p. 419-459, 2003.

ECHART, Enara; LÓPEZ, Sara; OROZCO, Kamala. Origen, protestas y propuestas del movimiento antiglobalización. Madrid: Catarata/UCM, 2005.

GADEA, Carlos. Acciones colectivas y modernidad global: el movimiento neozapatista. Toluca: Universidad Autónoma de Estado de México, 2004.

; SCHERER-WARREN, Ilse. A contribuição de Alain Touraine para o debate sobre sujeito e democracia latinoamericanos. Revista de Sociologia e Política, Curitiba, n. 25, nov., 2005 .

GOSS, Karine Pereira. Retóricas em disputa: o debate entre intelectuais em relação às políticas de ação afirmativa para estudantes negros no Brasil. 2008. Tese (Doutorado). Programa de Pós-Graduação em Sociologia Política, Universidade Federal de Santa Catarina. Florianópolis, 2008.

HALL, Stuart. Da diáspora: identidades e mediações culturais. Belo Horizonte: Ed. UFMG, 2003

JELIN, Elizabeth; HERSHBERG, Eric (Org.). Construindo a democracia: direitos humanos, cidadania e sociedade na América Latina. São Paulo: EDUSP, 2006.

KOROL, Claudia. La formación política de los movimientos populares latinoamericanos. Revista OSAL, Buenos Aires, CLACSO, v. 8, n. 22, set., 2007.

KECK, Margaret; SIKKINK, Kathryn. Activists beyond boarders: advocacy Networks in International Politics. Ithaca: Cornell University Press, 1998.

MACHADO, Jorge Alberto. Ativismo em rede e conexões identitárias: novas perspectivas para os movimentos sociais. Sociologias, Porto Alegre, v. 9, n. 18, p. 248-285 jul./dez., 2007.

MOUFFE, Chantal. Democracia, cidadania e a questão do pluralismo. Política e Sociedade: revista de Sociologia Política, Florianópolis, UFSC, v.1, n.3, 2003.

NIEMEYER, Carolina Burle de. Contestando a governanç global: a Rede Transnacional de Movimentos Sociais Via Campesina e suas relações com a FAO e OMC. 2006. Dissertação (Mestrado) Pontifícia Universidade Católica, Rio de Janeiro, 2006.

ORRICO ROCHA, Maria Neblina. Discurso e internet: o

caso do MST. Universidade de Brasília (UnB). In: CONGRESSO LUSO-AFRO-BRASILEIRO DE CIENCIAS SOCIAIS, 8. Coimbra, 2004.

ROSSIAUD, Jean; SCHERER-WARREN, Ilse. A democratização inacabável: as memórias do futuro. Petrópolis: Vozes, 2000. as e das emergências. Disponível em: www.ces.uc.pt/bss/ documentos/sociologia das ausencias.pdf. Acesso em: nov. 2008.

- Renovar a teoria crítica e reinventar a emancipaÇão social. São Paulo: Boitempo, 2007.

. As tensões da modernidade. Disponível em: www. forumsocialmundial. org.br/ 2004.

Reconhecer para libertar: os caminhos do cosmopolitismo cultural. Rio de Janeiro: Civilização Brasileira, 2003a.
Por uma concepção multicultural de direitos humanos. Rio de Janeiro: Civilização Brasileira, 2003b.

SCHERER-WARREN, Ilse. Movimentos sociais no Brasil contemporâneo. História: debates e tendências. [S.l.], Ed. da UPF, 2008 (no prelo).

. Fóruns e redes da sociedade civil: percepção sobre exclusão social e cidadania. Revista Política \& Sociedade. Florianópolis: PPGSP/UFSC, v. 6, n. 11, p.19-40, out. 2007a.

Redes sociais: trajetórias e fronteiras. In: DIAS, Leila Christina; SILVEIRA, Rogério L. L. da (Orgs.). Redes, sociedade e território. 2.ed. Santa Cruz do Sul: EDUNISC, 2007b.

Redes sociais e de movimentos. In: FERRARO JUNIOR, Luiz Antonio (Org.). Encontros e caminhos: formação de educadoras(es) ambientais e coletivos educadoras. Brasília: MMA, 2007c. v. 2. p. 323-332.

Das mobilizações às redes de movimentos sociais. Revista Sociedade e Estado, Brasília, v. 21, p. 109-130, 2006a.

Inclusão social e cidadania: a perspectiva das organizacões, redes e movimentos. In: AMARAL Jr, Aécio; BURITY, Joanildo (Org.). Inclusão social identidade e diferença-perspectivas pós-estruturalistas de análise social. São Paulo: Annablume, 2006b. p.125-138.

Redes sociales y de movimientos en la sociedad de la información. Nueva Sociedad, Venezuela, n. 196 mar./abr., 2006c.

Redes de movimentos sociais. 3.ed., São Paulo: Loyola, 2005.

Redes e sociedade civil global. In: HADDAD, S. (Org.). ONG's e universidades: desafios para a cooperação na América Latina. São Paulo: ABONG, 2002. p.63-92.

. Movimentos em cena... as teorias por onde andam? In: SCHERER-WARREN, Ilse, et al. Cidadania $e$ multiculturalismo: a teoria social no Brasil contemporâneo. Lisboa: Socius/Florianópolis: Ed. UFSC, 2000. p. 23-51.

Cidadania sem fronteiras: ações coletivas na era da globalização. São Paulo: Hucitec, 1999.

; KRISCHKE, Paulo (Org.) Uma revolução no cotidiano? Os novos movimentos sociais na América Latina. São Paulo: Brasiliense, 1986.

SILVEIRA, Suzana. A construção do sujeito no MST: assentamento Eldorado dos Carajás. 2007. Dissertação (Mestrado). Programa de Pós-Graduação em Sociologia Política, Universidade Federal de Santa Catarina. Florianópolis, 2007.

TOURAINE, Alain. O mundo das mulheres. Petrópolis: Vozes, 2007.

¿Podremos vivir juntos? La discusión pendiente: el destino del hombre en la aldea global. Buenos Aires:Fondo de Cultura Económica, 1997.

Actores sociales y sistemas politicos em America Latina. Chile, OIT/PREALC, 1987. 


\section{NETWORKS OF SOCIAL MOVEMENTS IN LATIN AMERICA. WAYS TOWARDS AN EMANCIPATORY POLICY?}

\author{
Ilse Scherer-Warren
}

This paper intends to bring some pointers on thinking in what measure the networks of social movements in Latin America present ways for emancipatory policies. To analyze the capacity or potential of social movements networks in this continent in the construction of emancipatory referencials, we started with the presupposition that material demands should be translated in symbolic representations, in order to approximate the actors to the networks, to allow the construction of collective identities and to create symbolic links of reference inside the networks, that make possible the convergence of their political lines. It was verified, still, how intersubjectivity is built in the networks starting from shared normative references and which are the main constituent levels for the empowerment of a movement network. Thus, we strive to verify how specific, located collective actors and with private demands become enlarged social movements of the point of view of their demands and of their territories of performance, with more universal policy lines. That is, how the passage of collective actions is being built restricted to social movements properly said.

KEYWORDS: networks of social movements, collective actions, Latin America, emancipation, demands.

\section{LES RÉSEAUX DE MOUVEMENTS SOCIAUX EN AMÉRIQUE LATINE. SONT-ILS LA VOIE D'UNE POLITIQUE EMANCIPATRICE?}

\author{
Ilse Scherer-Warren
}

Le propos de ce texte est d'apporter quelques éléments de réflexion pour savoir dans quelle mesure les réseaux des mouvements sociaux en Amérique Latine peuvent ouvrir des pistes à des politiques émancipatrices. Afin d'analyser la capacité ou le potentiel des réseaux de mouvements sociaux de ce continent, pour la construction de référentiels émancipatoires, on part du présupposé que les demandes matérielles doivent, d'une part, être traduites par des représentations symboliques, afin de rapprocher les acteurs des réseaux et, d'autre part, doivent permettre la construction d'identités collectives et créer des liens symboliques de référence au sein des réseaux, permettant une convergence de leurs enjeux politiques. Nous avons également pu vérifier comment se construit l'intersubjectivité dans le réseau, à partir de références normatives partagées, et quels sont les principaux niveaux qui permettent de s'approprier d'un réseau de mouvement. Il s'agit, en effet, de vérifier comment des acteurs collectifs spécifiques, localisés et qui ont des demandes particulières, se transforment en mouvements sociaux plus amples du point de vue de leurs demandes et de leurs domaines d'action, et dont les enjeux politiques sont plus universels. En d'autres termes, comment on passe d'une action collective limitée à un mouvement social proprement dit.

MoTS-CLÉs: réseaux de mouvements sociaux, actions collectives, Amérique Latine, émancipation, demandes

Ilse Scherer-Warren - Doutora em Sociologia pela Université de Paris X (Nanterre). É Professora Titular do Departamento de Sociologia e Ciência Política e coordena o Núcleo de Pesquisa em Movimentos Sociais (NPMS) da UFSC desde 1983. Pesquisadora IA do CNPq. Suas linhas de pesquisa versam sobre: movimentos sociais, redes, cidadania, globalização, ações coletivas e democracia. Entre suas principais publicações estão: "Movimentos sociais: um ensaio de interpretação sociológica" (Florianópolis, 1989), "Cidadania sem fronteiras: ações coletivas na Era da globalização" (São Paulo, 1999), "Redes de movimentos sociais" (São Paulo, 2005, $3^{\text {a }}$ edição) e várias publicações em revistas nacionais e internacionais. 